Equity Portfolio Management Using Option Price Information

\author{
Peter Christoffersen and Xuhui (Nick) Pan
}

CREATES Research Paper 2015-5 


\title{
Equity Portfolio Management Using Option Price Information*
}

\author{
Peter Christoffersen \\ Xuhui (Nick) Pan \\ Rotman School of Management, Freeman School of Business, \\ University of Toronto Tulane University
}

April 2, 2014

\begin{abstract}
We survey the recent academic literature that uses option-implied information to construct equity portfolios. Studies show that equity managers can earn a positive alpha by using information in individual equity options, by using stocks' exposure to information in market index options, and by using stocks' exposure to crude oil option information. Option-implied information can also help construct better mean-variance portfolios and better estimates of market beta.
\end{abstract}

JEL Classifications: G12.

Keywords: option-implied volatility; commodity futures; cross-section of stocks; optionimplied beta, mean-variance optimization.

\footnotetext{
${ }^{*}$ Christoffersen would like to thank Bank of Canada, Copenhagen Business School, CREATES and SSHRC for financial support. Correspondence to: Peter Christoffersen, Rotman School of Management, University of Toronto, 105 St. George Street, Toronto, Ontario, Canada, M5P 3E6; Tel: (416) 946-5511; Fax: (416) 971-3048; E-mail: peter.christoffersen@rotman.utoronto.ca.
} 


\section{Introduction}

It has long been recognized that options provide excellent forecasts of the future volatility on the underlying asset. Recent evidence include Busch, Christensen and Nielsen (2011). Academic researchers such as Bollerslev, Tauchen and Zhou (2009) have furthermore found evidence that option-implied volatility estimates from index options can help predict future returns on the market. Christoffersen and Pan (2014) find that option-implied oil volatility help forecast the overall stock market as well.

Recently, academics have begun to investigate if option prices contain information that is useful for equity portfolio allocation. They do; and we therefore provide an overview of this literature below. Three representative papers in the literature we survey are:

- Ang, Hodrick, Xing and Zhang (2006) who spearheaded the literature by showing that a stock's exposure to the option-implied stock market volatility, VIX, is an important determinant of its expected return.

- Conrad, Dittmar and Ghysels (2013) who report significant spreads in stock returns when sorting on firm-specific option-implied skewness and kurtosis using individual equity options.

- Christoffersen and Pan (2014) who in recent work find that stocks' exposure to crude-oil option volatility provides important information for equity portfolio management.

The literature we survey has two important features worth stressing at the outset. First, while various pieces of information from equity, index and commodity options are used below, options are not actually traded in any of the strategies we present. This is important because option spreads tend to be wider than the spreads on stocks and futures contracts. Second, the focus is on cross-sectional equity market prediction as opposed to time-series prediction: The articles we survey show that stocks with exposure to certain option-implied characteristics tend to perform better than other stocks on average through time.

Our article is structured as follows. In Section 2 we provide background on how option prices reveal information about the higher moments in stock returns. In Section 3 we survey studies that use individual equity options to extract information that can help generate alpha in a stock portfolio. In Section 4 we discuss papers that generate alpha by sorting stocks on their exposure to various information in market index options. In Section 5 we present new results that exploit stocks' exposure to option-implied volatility in crude oil, copper and gold options. In Section 6 we analyze how modern portfolio theory can be better implemented using option information. Finally, Section 7 concludes. 


\section{Option Smiles and Higher Moments}

Before we launch into the survey on cross-sectional equity returns, we briefly illustrate the relationship between volatility, skewness and kurtosis in the underlying stock and the BlackScholes implied volatility of the option on the stock.

Recall first the seminal Black and Scholes (1973) model in which the price of a call option is

$$
B S C a l l(\sigma)=S \exp (-\operatorname{div} T) \Phi(d)-K \exp (-r T) \Phi(d-\sigma \sqrt{T})
$$

where $\sigma$ is the volatility of the stock, $S$ is the stock price, $r$ is the risk-free rate, div is the dividend yield, $K$ is the strike price of the option, and $T$ is the time-to-maturity. The cumulative density of the standard normal distribution function is denoted by $\Phi(d)$, and we furthermore have used the definition

$$
d=\frac{\log (S / K)+\left(r-\operatorname{div}+\sigma^{2} / 2\right) T}{\sigma \sqrt{T}}
$$

which is sometimes used a measure of moneyness of the option.

The important thing to note is that there is a one-to-one relationship between stock volatility, $\sigma$, and the call price. Although not immediately obvious from the formulas above, the relationship is positive and close to linear for at-the-money options where $S / K$ is close to one.

In the Black-Scholes model, log returns are assumed to be normally distributed whereas in reality individual stock returns appear to have fat tails (excess kurtosis) and market index returns appear to be negatively skewed.

In order to capture these deviations from normality, one can rely on the approach in Backus, Foresi, Li and Wu (1997), who assume that the risk-neutral density of the underlying stock is approximated by an expansion around the normal distribution

$$
f(z)=\phi(z)-\frac{S k e w_{T}}{6} \frac{\partial^{3} \phi(z)}{\partial z^{3}}+\frac{\text { Kurt }_{T}}{24} \frac{\partial^{4} \phi(z)}{\partial z^{3}}
$$

where $z=(R-\mu T) /(\sigma \sqrt{T})$ is the standardized log return with mean $\mu$, and $\phi(z)$ is the normal density, and $S k e w_{T}$ and Kurt $_{T}$ denote skewness and excess kurtosis, respectively. ${ }^{1}$

Black-Scholes implied volatility $(B S I V)$ is defined as the level of volatility, $\sigma$, in the Black-Scholes model that would make the model option price exactly equal to the observed market price:

$$
\text { BSCall }(B S I V)=\text { MktCall }
$$

\footnotetext{
${ }^{1}$ Other popular expansions are surveyed in Christoffersen, Jacobs and Chang (2013).
} 
In reality, market prices on options do not obey the Black-Scholes model so that $B S I V$ will be different for different options quoted on the same stock.

Backus et al use equation (3) to derive a function describing the relationship between skewness and kurtosis in their model and Black-Scholes implied volatility. The relationship is

$$
B S I V(d) \approx \sigma\left[1-\frac{S k e w_{T}}{6} d-\frac{\text { Kurt }_{T}}{24}\left(1-d^{2}\right)\right] .
$$

In Figure 1 we use equation (4) to plot the Black-Scholes implied volatility for 30-daysto-maturity options as a function of option moneyness, defined as strike price over stock price, $K / S$ as is the convention in such plots. We set the risk-free rate to $3 \%$ per year and the dividend yield to $1 \%$ per year. In the top left panel we set skewness and kurtosis to zero. This would be the pattern if the Black-Scholes model correctly described market prices. In the top right panel annualized excess kurtosis is high at 3.5 but skewness is close to zero. This pattern is often referred to as an option "smile". In the bottom left panel, annualized skewness is -1.8 and excess kurtosis is close to zero. In the bottom right panel, annualized skewness is +1.8 and excess kurtosis is again close to zero. The patterns in the bottom two panels are commonly referred to as option "smirks".

The implied volatility pattern in the bottom-left panel of Figure 1 is very typical of S\&P500 index options. It shows that out-of-the-money (OTM) put options with $K / S<1$ are relatively expensive compared with at-the-money options. The market-crash insurance offered by OTM index puts is in excess demand, it is not easily hedged, and it therefore trades at high valuations.

The upshot of Figure 1 is that option prices and therefore Black-Scholes implied volatilities reveal important information about the skewness and kurtosis of the underlying stock. This is important because it is well-known in the econometric literature (see for example Kim and White, 2004) that it is very difficult to estimate higher moments even from long samples of returns on the underlying stock alone. Furthermore, we should expect the volatility, skewness and kurtosis of the underlying stock to be changing over time. This will make the information in option prices even more important because option prices will readily adjust to changes in the underlying moments, whereas the econometrician relying only on returns of the underlying stock will now need to build dynamic models for the higher moments of returns.

In summary, option prices convey important information about the inherent risks in the underlying stock. The remainder of this article surveys the literature that investigates if these risks are reflected in the pattern of stock returns across firms. 


\section{Using Information in Individual Equity Options}

In this section we review the empirical asset pricing literature that focuses on using information in individual equity options to find systematic patterns in stock returns across firms.

\subsection{Using the Relative Price of Put and Call Options}

Consider first a hypothetical frictionless markets, in which

- Perfectly liquid markets with no bid-ask spreads and no price impact of trades.

- Cash can be borrowed and lent at the single risk-free rate, $r$.

- Losses and gains are treated symmetrically for the purpose of taxes.

- Any risk-free arbitrage profits will be immediately traded away.

In this frictionless market, European style call and put option prices on the same underlying stock with price, $S$, and with the same maturity, $T$, and strike price, $K$, are related by the put-call parity

$$
S \exp (-\operatorname{div} T)+P u t=K \exp (-r T)+\text { Call }
$$

Note that the put-call parity does not rely on any particular pricing model such as BlackScholes. But any model that is built on no-arbitrage (such as Black-Scholes) will imply that the put-call parity holds. Note also that if the put-call parity holds for a particular set of call and put market prices then the $B S I V$ will be equal for those two options. This is because the $B S I V$ by definition makes the Black-Scholes model price equal to the market price. If equation (5) holds for both market prices and for Black-Scholes model prices, then a BSIV of e.g. $24 \%$ will set the Black-Scholes model price equal to the model price for both the call and the put option.

In reality, individual equity options are American style which can be exercised any time before expiration, whereas the put-call parity is only valid for European style options in which early exercise is not possible. Furthermore, any of the assumptions made above about frictionless markets are likely to be violated at any given time.

The put-call parity represents a useful (even if hypothetical) benchmark to assess if the relative pricing of call and put options contain information about the underlying stock. Cremers and Weinbaum (2010) follow this approach and use the difference in implied volatility between call and put options with the same maturity and strike to investigate the pattern in returns on the underlying stock going forward. 
Each Wednesday during 1996 to 2005 they sort the cross-section of approximately 2, 000 stocks into five quintile portfolios based on the average difference between all valid pairs of call and put $B S I V$ s on each stock. They then keep track of the value-weighted return on each quintile portfolio during the following one-week and four-week holding periods.

In order to assess the risk-adjusted (excess) return on each quintile portfolio they run the following time-series regression

$$
R_{j, t}-r_{t}=\alpha_{j}+\beta_{j, 1} R_{m k t, t}+\beta_{j, 2} R_{s i z e, t}+\beta_{j, 3} R_{\text {value }, t}+\beta_{j, 4} R_{m o m, t}+e_{j, t}, \text { for } j=1,2, \ldots, 5
$$

and report the alpha, that is the constant term which represents the part of the average return on the portfolio that is not captured by the risk factors. As is standard in this literature they use the market (less risk-free) excess return, size, value and momentum factors popularized by Fama and French (1993) and Carhart (1997). ${ }^{2}$ Figure 2 plots the cumulative returns over time on these four standard risk factors. All four panels use the same scale on the vertical axis so as to facilitate comparison. Note that the performance of each risk factor can vary considerably depending on sample period used. Note in particular the spectacular performance of the momentum factor until March 2009 and the equally spectacular drop shortly after. The momentum factor requires monthly rebalancing and has much higher turnover than do the value and size factors which are only rebalanced annually.

In order to capture higher moments, Cremers and Weinbaum (2010) also include the co-skewness factor from Harvey and Siddique (2000) as a risk factor.

Panel A in Table 1 presents the key results from Cremers and Weinbaum (2010). The long-short portfolio that goes long the 5th quintile portfolio and short the 1st quintile portfolio obtains an average four-week holding-period return of 40 bps which is significant with a t-statistic of 3.12. The corresponding alpha is 51 bps which is again significant. The one-week holding-period average return is 20 bps and the alpha is 21 bps both of which are significant as well. Note also that the patterns in average returns and alphas are fairly monotone across the five quintile portfolios.

\section{$3.2 \quad$ Using Equity Option Volatility Smiles}

In a contemporary paper, Xing, Zhang, and Zhao (2010) each week during 1996 to 2005 sort about 840 stocks into five quintile portfolios based on the slope of the $B S I V$ curve (that is the market-based version of the "smile" or "smirk" in Figure 1) which they compute using the difference between the $B S I V$ of the out-of-the-money (OTM) put with $K / S$ closest to

\footnotetext{
${ }^{2}$ For classic references on the size factor, see Banz (1981); for the value factor, see Rosenberg, Reid, and Lanstein (1985); and for momentum, see Jegadeesh and Titman (1993).
} 
0.95 and at-the-money (ATM) call with $K / S$ closest to 1 . Note that stocks can have nonzero option-implied skewness while still not violating the put-call parity. Xing, Zhang, and Zhao (2010) and thus not investigating the same effect as Cremers and Weinbaum (2010).

Panel B in Table 1 reports weekly excess returns and Fama-French three-factor alphas (excluding momentum) of quintile portfolios sorted on the previous week's option skew. Portfolio 1 contains the firms with lowest levels of skewness, and portfolio 5 contains firms with the highest levels of skewness. Panel B shows that the quintile of stocks with the lowest (largest negative) option-implied skewness outperform the stocks with the highest option-implied skewness by 16 bps per week with a corresponding alpha of 21 bps.

Xing, Zhang, and Zhao (2010) also compute the slope of the smile using a volumeweighted measure in which they use option trading volume as a weight across available OTM puts and ATM calls. If an option has zero volume then its weight will be zero and it will be excluded from the analysis. The quintile portfolio returns from the volume-based slopes in Panel B are quite similar to the simple moneyness sorts discussed above.

\subsection{Using Higher Moments Implied in Equity Options}

Conrad, Dittmar, Ghysels (2013) compute model-free option-implied volatility, skewness and kurtosis each month during 1996 to 2005 for each of approximately 307 stocks using all the available options on each stock during the month. The methodology they use to compute the moments is due to Bakshi and Madan (2000) and Carr and Madan (2001).

Panel C of Table 1 reports the following month's return and characteristic-adjusted return of portfolios sorted into terciles based on this month's option-implied volatility, skewness, or kurtosis which are all computed using the closest to 3 -month contracts. ${ }^{3}$ Returns are characteristic-adjusted by subtracting the return of the Fama and French (1993) $5 \times 5$ size and book-to-market portfolios to which each firm belongs. The t-statistics are again reported in parenthesis.

Panel $\mathrm{C}$ in Table 1 shows that the portfolio that goes long the tercile of stocks with the lowest volatility and short the tercile of stocks with the highest volatility earns 56 bps per month, although this return is not statistically significant nor is its characteristic-adjusted counterpart. Sorting on option-implied skewness earns a large and significant return. The tercile spread return is 82 bps per month when going long stocks with small (that is large negative) skewness and short stocks with high skewness. The tercile spread on optionimplied kurtosis is also large and significant at 72 bps: Stocks with large kurtosis on average

\footnotetext{
${ }^{3}$ Sorting on stocks' exposure to equity option-implied volatility is also done in Bali and Hovakimian (2009).
} 
outperform stocks with low kurtosis.

In summary, Cremers and Weinbaum (2010) sort stocks on their deviations from put-call parity, whereas Xing, Zhang and Zhao (2010) sort on the slope of the smile, and Conrad, Dittmar and Ghysels (2013) sort stocks on their option implied moments. All three approaches are able to generate a significant spread in the returns on underlying stock portfolios. An investigation of the performance of these portfolios after 2005 would clearly be of significant interest.

\section{Using Information in Market Index Options}

The discussion so far has focused on methods where individual equity option prices are required. This limits the analysis to countries with sufficiently rich and liquid equity option markets. It is therefore of considerable interest to investigate if market index options can be used for equity portfolio selections. Market index options are typically much more liquid than individual equity options and they are by now available in all major economies including Canada. In this section we therefore assess the ability of the VIX, the market SKEW and the market variance risk premium (VRP) to help build equity portfolios with superior riskadjusted performance.

\subsection{Using Stocks' Exposure to the VIX}

It is clear that in order to use the information on market index options in the cross-section of equity options, we need to first estimate the exposure of each stock to the market-wide option information. This is typically done using simple regressions for the return of stock $i$ of the form

$$
R_{i, t}-r_{t}=\beta_{0}^{i}+\beta_{m k t}^{i} R_{m k t, t}+\beta_{\Delta O I}^{i} \Delta O I_{t}+\epsilon_{i, t}
$$

where $\Delta O I_{t}$ captures innovations (news) in the option implied variable. The innovation is often computed by simply taking the first-differences of the option implied variable itself which implies that it is a random walk.

Note that the beta estimation regression in (6) provides us with the information we need to sort the stocks: Each stock will have a different $\beta_{\Delta O I}^{i}$ which can in turn be used to sort the stocks into quintile portfolios based on their exposure to the market-wide option implied risk factor at hand.

Ang, Hodrick, Xing and Zhang (2006) were to our knowledge the first to implement an option-implied risk factor in the academic literature. They used the daily change in 
the Chicago Board Options Exchange (CBOE) volatility index, VIXt, as the market-wide option-implied risk factor. ${ }^{4}$

The top panel of Figure 3 shows the VIX $X_{t}$ plotted from 1990 through 2012. Note the peak during the financial crises in the fall of 2008 as well as the long periods of low option-implied market volatility during the bull markets in the mid 1990s and the mid 2000s.

Panel A of Table 2 reports the monthly average return and Fama-French three-factor alphas from Ang, Hodrick, Xing and Zhang (2006) for the 1986 to 2000 period. Each month, they regress daily excess returns from all stocks on NYSE/AMEX/NASDAQ on $\Delta V I X_{t}$ to get the $\beta_{\Delta V I X}^{i}$ for each stock. They use a rolling sample of 30 calendar days to estimate each beta. The following month's average return on each quintile portfolio is then reported in Panel A of Table 2. Note that an equity strategy that goes long stocks with the lowest (largest negative) beta with changes in the VIX and short stocks with the largest beta earn on average 104 bps per month with an alpha of 83 bps. Both return measures are significant as the t-statistics in the parentheses show. Stocks that have a large (positive) exposure to changes in the VIX may be a good hedge against shocks to economic uncertainty and they are therefore priced relatively rich and earn a low average return.

Note that the returns and alphas across the VIX-beta quintiles in Panel B of Table 2 are monotone, but do also note the considerable discontinuity between quintile 4 and 5 : The spreads in returns and alphas are driven to a considerable degree by quintile 5 which must be sold short in the spread return strategy.

\subsection{Using Stocks' Exposure to Market Skewness}

The CBOE have been publishing the VIX index since 1986 and it has more recently begun constructing and publishing option-implied skewness on the S\&P500 index, which we will analyze now, but also option-implied volatility on other asset classes such as commodities which we will investigate further below.

The option-implied S\&P500 SKEW index from the CBOE is reported as

$$
\text { SKEW Index }=100-10(\text { OISkew })
$$

and it is plotted in the middle panel of Figure 3. The option-implied skewness, OISkew, is computed using a methodology similar to that used to compute the $V I X{ }^{5}$ Note that S\&P 500 index option skewness is virtually always estimated to be negative which translates into a positive number in the CBOE $S K E W$ index definition as is evident from Figure 3.

\footnotetext{
${ }^{4}$ For details, see http://www.cboe.com/micro/vix/vixwhite.pdf.

${ }^{5}$ For details, see http://www.cboe.com/micro/skew/documents/SKEWwhitepaperjan2011.pdf.
} 
Figure 3 also shows that there is no obvious relationship between the $V I X$ in the top panel and the $S K E W$ index in the middle panel. The $S K E W$ index thus may contain important information about risk which is not contained in the $V I X$.

Chang, Christoffersen, and Jacobs (2013) use the methodology in Bakshi and Madan (2000) and Carr and Madan (2001) to construct their own option-implied skewness series from S\&P 500 index options. They then regress daily excess returns from all stocks on NYSE/AMEX/NASDAQ on daily changes in option-implied skewness to get a $\beta_{\triangle S K E W}^{i}$ for each stock each month.

Panel B of Table 2 presents the next month average return and Fama-French (1993) and Carhart (1997) four-factor alpha for the quintile portfolios sorted on this month's $\beta_{\Delta S K E W}^{i}$. Panel B shows that stocks with low (negative) $\beta_{\Delta S K E W}^{i}$ earn an average return of 122 bps versus stocks with high $\beta_{\triangle S K E W}^{i}$ which earn an average of 63 bps per month. The difference is marginally significant and the associated alpha is strongly significant at 80 bps per month.

\subsection{Using Stock's Exposure to the Variance Risk Premium}

Bollerslev, Tauchen and Zhou (2009) have found that the variance risk premium (VRP) computed from S\&P500 index options help predict the overall market return next month. This suggests that the VRP is a risk factor in the equity market. Christoffersen, Heston and Jacobs (2013) analyze how the $V R P$ is related to the standard equity premium in option valuation models with stochastic volatility.

The $V R P$ is broadly defined as the difference between option-implied variance and realized variance. We compute in as follows: At the end of each month we use $V I X_{t}$ to get option-implied annualized variance

$$
\operatorname{IVar}_{t}=\left(\operatorname{VIX} X_{t} / 100\right)^{2}
$$

We then compute realized variance as the annualized squared end-of-month return of the monthly S\&P 500 index $^{6}$

$$
R \operatorname{Var}_{t}=(252 / 21) R_{t}^{2}
$$

Finally we compute the variance risk premium as

$$
V R P_{t}=100\left(\operatorname{IVar}_{t}-R \operatorname{Var}_{t}\right)
$$

The bottom panel of Figure 3 plots the VRP from 1990 through 2012. While some relationship is apparent with VIX in the top panel is clear. It is of course to be expected

\footnotetext{
${ }^{6}$ Often daily or intra-day returns are used to compute realized variance. See for example, Bollerslev, Tauchen, and Zhou (2009).
} 
as VIX ${ }^{2}$ is used to compute VRP. Nevertheless, much independent variation is also evident and an investigation of VRP as a risk factor is justified.

Bali and Zhou (2013) undertake such an analysis and Panel C in Table 2 contains their main results. Rather than working with individual equity returns, which can be noisy, they use returns on $5 \times 5=25$ and $10 \times 10=100$ size and book-to-market portfolios. Rather than using simple regressions to obtain the $\beta_{\Delta V R P}^{i}$ exposure they use a dynamic variance and correlation model.

Panel C of Table 2 contain the monthly average excess returns and Fama-French (1993) three-factor alphas of the $\beta_{\Delta V R P}^{i}$ quintile portfolios. Note that the $5-1$ spread portfolio return is either 49 bps (for the 100 test portfolios) or 58 bps (for the 25 test portfolios) and both numbers are significant as are their 3-factor alphas.

\section{$5 \quad$ Using Information in Crude Oil Options}

In this section we summarize our recent work in Christoffersen and Pan (2014) in which we investigate if stocks' exposure to uncertainty in the oil price determines their return on average. Below we also outline various potential extensions to other commodities. This line of research is interesting because presumably individual stocks from around the world-and perhaps particularly in commodity producing economies such as Canada-would be exposed to the same commodity risk factors.

\subsection{Option-Implied Oil Volatility}

The CBOE has recently begun computing and publishing an "oil VIX" with the ticker $O V X .^{7}$ The $O V X$ measures option-implied volatility using 30-day options on United States Oil Fund (USO) which is a large exchange traded fund (ETF) with about a $\$ 500$ million market cap invested in near-term crude oil futures trading on the Chicago Mercantile Exchange (CME). Options spanning a wide range of strike prices trade on the USO. These options are used by the CBOE to compute $O V X$ using the VIX methodology. USO must roll-over its futures positions to the second-nearest maturity when the nearest-to-maturity contract gets close to expiration. ${ }^{8}$

The grey line in the top panel of Figure 4 shows the $O V X$ as computed by the CBOE. The $O V X$ is only available from May 10, 2007. We therefore use the methodology described in Bakshi and Madan (2000) and Carr and Madan (2001) to compute option-implied oil

\footnotetext{
${ }^{7}$ For details, see https://www.cboe.com/micro/oilvix/introduction.aspx.

${ }^{8}$ See https://www.cboe.com/micro/uso/ for details on the USO.
} 
volatility (IVOil) from options trading on crude-oil futures which we obtain from the CME (formerly NYMEX). These futures options are American style and we convert them to European style by subtracting an early exercise premium computed using the Barone-Adesi and Whaley (1987) formula.

The black line in the top panel of Figure 4 shows the IVOil series we construct from January 2, 1990. Due to the structural changes in the commodity futures markets occurring in the early 2000s, we restrict attention to the 2005-2012 period below. ${ }^{9}$ The start of this period is marked by the vertical line in Figure 4.

\subsection{Using Stocks' Exposure to Option-Implied Oil Volatility}

Once IVOil has been computed, the next step is to compute the exposure of each stock to unexpected changes in IVOil. To this end we run for each firm the regression

$$
R_{i, t}-r_{t}=\beta_{0}^{i}+\beta_{m k t}^{i} R_{m k t, t}+\beta_{\Delta I V O i l}^{i} \Delta I V O i l_{t}+\epsilon_{i, t},
$$

where we have assumed that $I V O i l_{t}$ is a random walk so that any change is unexpected. We estimate $\beta_{\Delta I V O i l}^{i}$ each month for each stock using daily stock returns and daily $\Delta I V O i l_{t}$ within the month. We then check if on average stocks' exposure to $\Delta I V O i l_{t}$ is reflected in the cross-firm patterns in stock returns in the following month.

Panel A of Table 3 reports expected returns and alpha of portfolios sorted on innovations in IVOil. We form five value-weighted portfolios at the end of each month and record the daily returns of each quintile portfolio for the following month. We repeat the procedure by rolling the beta estimation window forward one month at a time. The table reports the average monthly returns for each quintile portfolio, as well as the alpha based on the Carhart four-factor model. T-statistics for the alphas are reported in parentheses. T-statistics larger than 1.68 in magnitude are reported in boldface due to the short nature of our sample. Panel A shows that the average return on stocks in the quintile with the lowest $\beta_{\Delta I V O i l}^{i}$ is 108 bps compared with 42 bps per month for stocks with the highest $\beta_{\Delta I V O i l}^{i}$. The spread of 66 bps per month is strongly significant. The Carhart 4-factor alpha is $75 \mathrm{bps}$ and it is not as strongly significant due to the added sampling error when estimating Carhart factor loadings. Note that the returns and alphas are both decreasing in a monotone fashion across quintiles as the $\beta_{\Delta I V O i l}^{i}$ increases. Stocks with a high $\beta_{\Delta I V O i l}^{i}$ do well when oil volatility increases. They are viewed by investors as being good hedges against economic uncertainty shocks, they therefore trade at relatively high valuation and offer relatively low returns on average.

\footnotetext{
${ }^{9}$ For a discussion of the impact of the financialization of commodity markets, see Tang and Xiong (2012) and Cheng and Xiong (2013).
} 


\subsection{Other Commodities}

Given the success of option-implied oil volatility as a risk-factor in the equity market, it is natural to wonder if other commodity options work as well. To this end we use the methodology in the Bakshi and Madan (2000) and Carr and Madan (2001) to compute option-implied gold price and copper price volatility from the respective futures options.

The black line in the middle panel in Figure 4 shows our IVGold volatility from 1990 through 2012. While some similarities with IVOil in the top panel are evident, there is clearly much independent variation. The grey line in the middle panel shows the "gold VIX" published by the CBOE, who compute it using 30-day options on the SPDR Gold Shares ETF. ${ }^{10}$ Note again that our series is close to the CBOE index.

The bottom panel in Figure 4 plots option-implied volatility on copper, IVCopper, which we again compute from futures options since 1990. Note that for copper we do not have a CBOE index available for comparison.

Panel $\mathrm{B}$ and $\mathrm{C}$ in Table 3 report expected returns and alpha of portfolios sorted on innovations in IVGold and IVCopper, respectively. Note that while the monthly 5-1 quintile return spreads are positive, they are not statistically significant. The point estimate is fairly large for gold at 53 bps but smaller for copper at 31 bps. The alphas are not significant either, although IVGold has an alpha of 54 bps with a t-statistic of 1.61 which is close to our cut-off of 1.68 .

In summary, it seems, perhaps not surprisingly, that crude oil is the most important commodity risk factor for the equity market. Interestingly, while we find that innovations to IVOil is a priced factor in the equity markets, innovations to the oil price itself is not (see Christoffersen and Pan, 2014). The stock market appears to care more about the oil uncertainty shocks captured by $\triangle I V O i l$ than it cares about oil shocks themselves. Going forward it will be interesting to investigate if other commodities are important equity risk factors.

\section{Other Investment Applications of Option Informa- tion}

So far we have focused on using option information to find cross-firm patterns in average stock returns and alphas. In this Section we survey the recent academic literature that uses option-implied information to guide two different but related aspects of portfolio allocation.

\footnotetext{
${ }^{10}$ For details, see https://www.cboe.com/micro/gvz/introduction.aspx.
} 
First, we look at mean-variance allocations using option information. This is clearly useful for portfolio construction. Second, we see how CAPM betas for individual firms, which are typically computed using regressions on historical returns as we did above, can be computed instead using just one day of equity and index option data. This is useful for performance evaluation and cost-of-capital computations.

\subsection{Mean-Variance Allocation using Option Information}

The Nobel-prize winning contribution of Markowitz $(1952,1959)$ was to show that an investor with mean-variance preference should construct a portfolio with the following weights in the $N$ available risky assets

$$
W=\frac{1}{\gamma} \Sigma^{-1}(\mu-r)
$$

and then invest the remaining of his/her wealth in risk-free bonds earning the risk-free rate $r$. With a sufficiently low risk-aversion, $\gamma$, the investor may be leveraged with the necessary funds borrowed at a rate of $r$ instead. The Markowitz allocation incorporates information on diversification benefits via the variance-covariance matrix $\Sigma$ as well as on the vector of assets' expected returns, $\mu$.

While the Markowitz formula is a cornerstone of modern portfolio theory, it is extremely tricky to implement in practice. The $\mu$ vector and the $\Sigma$ matrix must both be estimated and will therefore contain estimation error. The nonlinearity of the formula in (8) compounds the seemingly inevitable problems from estimation error. Brandt (2010) contains an excellent overview of these so-called "error-maximization" problems in investment management and suggests various potential econometric fixes.

The Markowitz allocation in (8) in theory maximizes the Sharpe-ratio of the portfolio. In practice, the simple equal-weighted portfolio in which

$$
W_{i}=1 / N, \quad i=1,2, \ldots, N
$$

typically works better for maximizing the Sharpe-ratio than does the theoretically optimal allocation in equation (8). See for example, DeMiguel, Garlappi and Uppal (2009).

Recently, DeMiguel, Plyakha, Uppal, Vilkov (2014) show that all is not lost: One can increase the Sharpe ratio of a mean-variance portfolio of stocks when using option-implied volatility and skewness estimates. In Table 4 we report some of the key results from DeMiguel et al. (2014). Table 4 reports the out-of-sample Sharpe ratio of six different portfolio strategies

- The $1 / N$ portfolio in equation (9). 
- A shortsale-constrained minimum-variance portfolio. That is, the allocation in (8), but imposing that $W_{i} \geq 0, \quad i=1,2, \ldots, N$.

- Four different shortsale-constrained, mean-variance portfolios based on $\mu$ vectors in equation (8) that are adjusted using option-implied information.

The bold-face numbers in Table 4 indicate that the portfolio performs significantly better than the benchmark $1 / N$ portfolio and the constrained minimum-variance portfolio reported in the first two rows. Sample 1 in the left column of Table 4 includes 143 stocks in the S\&P 500 index for which implied volatilities are available. Sample 2 includes all the stocks that are part of the S\&P500 index on a particular day and have no missing option data on that day. The sample covers the period from January 1996 to October 2010.

In addition to the work by DeMiguel et al. (2014) discussed above, Kostakis, Panigirtzoglou, and Skiadopoulos (2011) have recently argued that investors can achieve better portfolio performance by using option-implied distributions compared with historical return distributions. Kempf, Korn, and Sassning (2014) use option-implied moments to estimate the covariance matrix and show that a minimum-variance strategy outperforms other benchmark strategies, including those based on historical estimates, index investing, and $1 / N$ investing. Brandt, Santa-Clara and Valkanov (2009) provide an alternative to the Markowitz-allocation, which is very practical and can be used to incorporate option-implied information into largescale portfolios.

Going forward, we expect to see much more research in this new and promising area.

\subsection{Option-Implied Market Betas}

We now turn to our final application of option implied information in investment management. Consider, first the benchmark CAPM model, where

$$
R_{i}-r=\beta_{0}^{i}+\beta_{m k t}^{i} R_{m k t}+\epsilon_{i}
$$

The market beta parameter is typically estimated by

$$
\beta_{m k t}^{i}=\frac{\operatorname{Cov}\left(R_{i}, R_{m k t}\right)}{\operatorname{Var}\left(R_{m k t}\right)}=\operatorname{Corr}\left(R_{i}, R_{m k t}\right)\left(\frac{\operatorname{Var}\left(R_{i}\right)}{\operatorname{Var}\left(R_{m k t}\right)}\right)^{1 / 2}
$$

using a historical sample of daily or monthly returns.

In many cases, however, the historical returns may not be representative of the firms'

risk going forward. This is the case for example for firms with recently reorganized balance sheets or operations, or for firms facing a new competitive environment caused, for example, by new market entrants. 
Chang, Christoffersen, Jacobs, and Vainberg (2012) show that the CAPM beta can be estimated from a single day of options under the following assumptions: If the stock has zero co-skewness and zero idiosyncratic skewness, then we can write a beta estimate based on skewness and volatility as

$$
\beta_{m k t}^{i, O I}=\left(\frac{\operatorname{Skew}\left(R_{i}\right)}{\operatorname{Skew}\left(R_{m k t}\right)}\right)^{1 / 3}\left(\frac{\operatorname{Var}\left(R_{i}\right)}{\operatorname{Var}\left(R_{m k t}\right)}\right)^{1 / 2}
$$

Recall from the discussion in Section 2 above that the option-implied variance captures the level of the $B S I V$ curve and option-implied skewness captures the slope of the $B S I V$ curve when $B S I V$ is plotted against $K / S$ on the horizontal axis as we did in Figure 1 . The option-implied beta in equation (12) is thus based on the relative slopes of the $B S I V$ curves for equity and index options (to the power of $1 / 3$ ) multiplied by the relative levels of the $B S I V$ curves from equity and index options. ${ }^{11}$

Buss and Vilkov (2012) develop further the idea in Chang, Christoffersen, Jacobs, and Vainberg (2012) by deriving an explicit parametric form of option-implied correlations and using those to construct option-implied market betas. They confirm that the relation between risk and returns embedded in market betas is monotonically increasing.

Table 5 presents market betas and average returns based on historical and option-implied information from Buss and Vilkov (2012). At the end of each month, stocks are sorted into quintiles based on their estimated market beta, with the first portfolio containing the stocks with the lowest market betas, and the fifth portfolio containing the stocks with the highest market betas. Then the value-weighted expected portfolio market beta and the annualized value-weighted realized return over the next month are recorded. This table reports the timeseries means of estimated beta and the annualized mean realized return for the five quintile portfolios sorted on market beta. The sample period is from January 1996 to December 2009.

Panel A of Table 5 shows that higher beta portfolios have higher average returns in daily data for both the traditional beta estimates and for the option-implied beta estimates. Panel B of Table 5 shows that for monthly data this is also the case for option-implied betas but not for the traditional historical betas. The historical betas instead deliver the counter-CAPM prediction that we should "bet against beta" as suggested recently by Frazzini and Pedersen (2014). Buss and Vilkov (2012) instead show that when option-implied betas are used, the traditional CAPM prediction holds: The higher the beta, the higher the average return.

\footnotetext{
${ }^{11}$ For more details on this implementation, see Fouque and Kollman (2011).
} 


\section{Summary}

In this article we have surveyed the recent empirical literature on cross-sectional equity pricing that incorporates option-implied information.

The literature using individual equity options finds evidence that the following factors are priced in the stock market:

- The relative price of call and put options on the same stock.

- The slope of the implied volatility curve for individual stocks.

- The option-implied skewness and kurtosis in individual equity options.

When looking at the literature that sort stocks based on their exposure to market index options, we find:

- Stocks with low (large negative) beta with innovations in VIX earn higher returns.

- Stocks with low (large negative) beta with innovations in the market $S K E W$ earn higher returns.

- Stocks with high exposure to the market variance risk premium earn higher returns.

When considering stocks exposure to innovations in option-implied commodity volatility, we find:

- Stocks with low (large negative) beta with innovations in oil volatility risk earn higher returns.

- Stocks' exposure to gold and copper volatility risk does not seem to be priced in the cross section of stocks.

Finally, we find evidence that option-implied information can be used to improve portfolio allocations via improved estimates of asset expected returns, volatilities, correlations and betas. 


\section{References}

Ang, A., Hodrick, R. J., Xing, Y., Zhang, X., 2006. The cross-section of volatility and expected returns. Journal of Finance 11, 259-299.

Backus, D., Foresi, S., Li, K., Wu, L., 1997. Accounting for biases in Black-Scholes. Working paper, New York University

Bakshi, G., Kapadia, N., Madan, D., 2003. Stock return characteristics, skew laws, and the differential pricing of individual equity options. Review of Financial Studies 16, 101-143.

Bakshi, G., Madan, D., 2000. Spanning and derivative security valuation. Journal of Financial Economics 55, 205-238.

Bali, T., Hovakimian, A., 2009. Volatility spreads and expected stock returns, Management Science 55, 1797-1812.

Bali, T., Zhou, H., 2013. Risk, uncertainty, and expected returns. Working Paper, Georgetown University.

Banz, R., 1981. The relationship between return and market value of common stock, Journal of Financial Economics 9, 3-18.

Barone-Adesi, G., Whaley, R., 1987. Efficient analytic approximation of American option values. Journal of Finance 42, 301-320.

Black, F., Scholes., M, 1973. The pricing of options and corporate liabilities. Journal of Political Economy 81, 637-654.

Bollerslev, T., Tauchen, G. , Zhou, H., 2009. Expected stock returns and variance risk premia. Review of Financial Studies 22, 4463-4492.

Brandt, M., 2010. Portfolio choice problems, in Y. Ait-Sahalia and L.P. Hansen (eds.), Handbook of Financial Econometrics, Volume 1: Tools and Techniques, North Holland, pp. 269-336.

Brandt, M., Santa-Clara, P., Valkanov, R., 2009. Parametric portfolio policies: exploiting characteristics in the cross section of equity returns. Review of Financial Studies 22, 3411-3447.

Busch, T., Christensen, B. J., Nielsen, M., 2011. The role of implied volatility in forecasting future realized volatility and jumps in foreign exchange, stock, and bond markets. Journal of Econometrics 160, 48-57. 
Buss, A., Vilkov, G. 2012. Measuring equity risk with option-implied correlations, Review of Financial Studies 25, 3113-3140.

Carhart, M., 1997. On persistence of mutual fund performance. Journal of Finance 52, 57-82.

Carr, P., Madan, D., 2001. Optimal positioning in derivative securities. Quantitative Finance $1,19-37$.

Chang, B.Y., Christoffersen, P., Jacobs, K., 2013. Market skewness risk and the cross section of stock returns. Journal of Financial Economics 107, 46-68.

Chang, B.Y., Christoffersen, P., Jacobs, K., Vainberg, G., 2012. Option-implied measures of equity risk. Review of Finance 16, 385-428.

Cheng, I.-H., Xiong, W., 2013. The financialization of commodity markets. Working paper, Princeton University

Christoffersen, P., Heston, R., Jacobs, K., 2013. Capturing option anomalies with a variancedependent pricing kernel. Review of Financial Studies 26, 1963-2006.

Christoffersen, P., Jacobs, K., Chang, B. Y., 2013. Forecasting with option implied information, Handbook of Economic Forecasting, edited by G. Elliott and A. Timmermann, Volume 2, Chapter 10, pp. 581-656, Elsevier.

Christoffersen, P., Pan, X., 2014. Oil volatility risk and expected stock returns. Working paper. University of Toronto.

Conrad, J., Dittmar, R., Ghysels, E., 2013. Ex ante skewness and expected stock returns. Journal of Finance 68, 85-124.

Cremers, M., Weinbaum, D., 2010. Deviations from put-call parity and stock return predictability, Journal of Financial and Quantitative Analysis 45, 335-367.

DeMiguel, V., Garlappi, L., Uppal, R., 2009. Optimal versus naive diversification: how inefficient is the 1/N portfolio strategy? Review of Financial Studies 22, 1915-1953.

DeMiguel, V., Plyakha, Y., Uppal, R., Vilkov, G., 2014. Improving portfolio selection using option-implied volatility and skewness, Journal of Financial and Quantitative Analysis, forthcoming.

Duan, J.C., Wei, J., 2009. Systematic risk and the price structure of individual equity options. Review of Financial Studies 22, 1981-2006. 
Fama, E. F., French, K. R., 1993. Common risk factors in the returns on stocks and bonds. Journal of Financial Economics 33, 3-56.

Fouque, J.-P., and Kollman, E., 2011. Calibration of stock betas from skews of implied volatilities. Applied Mathematical Finance 18, 119-137.

Frazzini, A., Pedersen, L. H., 2014. Betting against beta. Journal of Financial Economics $111,1-25$.

Harvey, C., Siddique. A., 2000. Conditional skewness in asset pricing tests. Journal of Finance $55,1263-1295$.

Jegadeesh, N., and Titman, S., 1993. Returns to buying winners and selling losers: Implications for stock market efficiency, Journal of Finance 48, 65-91.

Kempf, A., Korn, O., and Sassning, S., 2014. Portfolio optimization using forward-looking information, Review of Finance, forthcoming.

Kim, T.-H., and White, H., 2004. On more robust estimation of skewness and kurtosis, Finance Research Letters 1, 56-73.

Kostakis, A., Panigirtzoglou, N., Skiadopoulos, G., 2011. Market timing with option-implied distributions: a forward-looking approach. Management Science 57, 1231-1249.

Markowitz, H., 1952. Portfolio selection. Journal of Finance 1, 77-91.

Markowitz, H., 1959. Portfolio selection: efficient diversification of investments. John Wiley \& Sons, Inc., New York, Chapman \& Hall, Limited, London

Rosenberg, B., Reid, K., and Lanstein, R., 1985. Persuasive evidence of market inefficiency. Journal of Portfolio Management 11, 9-17.

Tang, K., Xiong,W., 2012. Index investing and the fiancialization of commodities. Financial Analysts Journal 68, 54-74.

Xing, Y., Zhang, X., Zhao, R., 2010. What does the individual option volatility smirk tell us about future equity returns? Journal of Financial and Quantitative Analysis 45, 641-662. 
Figure 1: Black-Scholes Implied Volatility Smiles and Higher Moments.
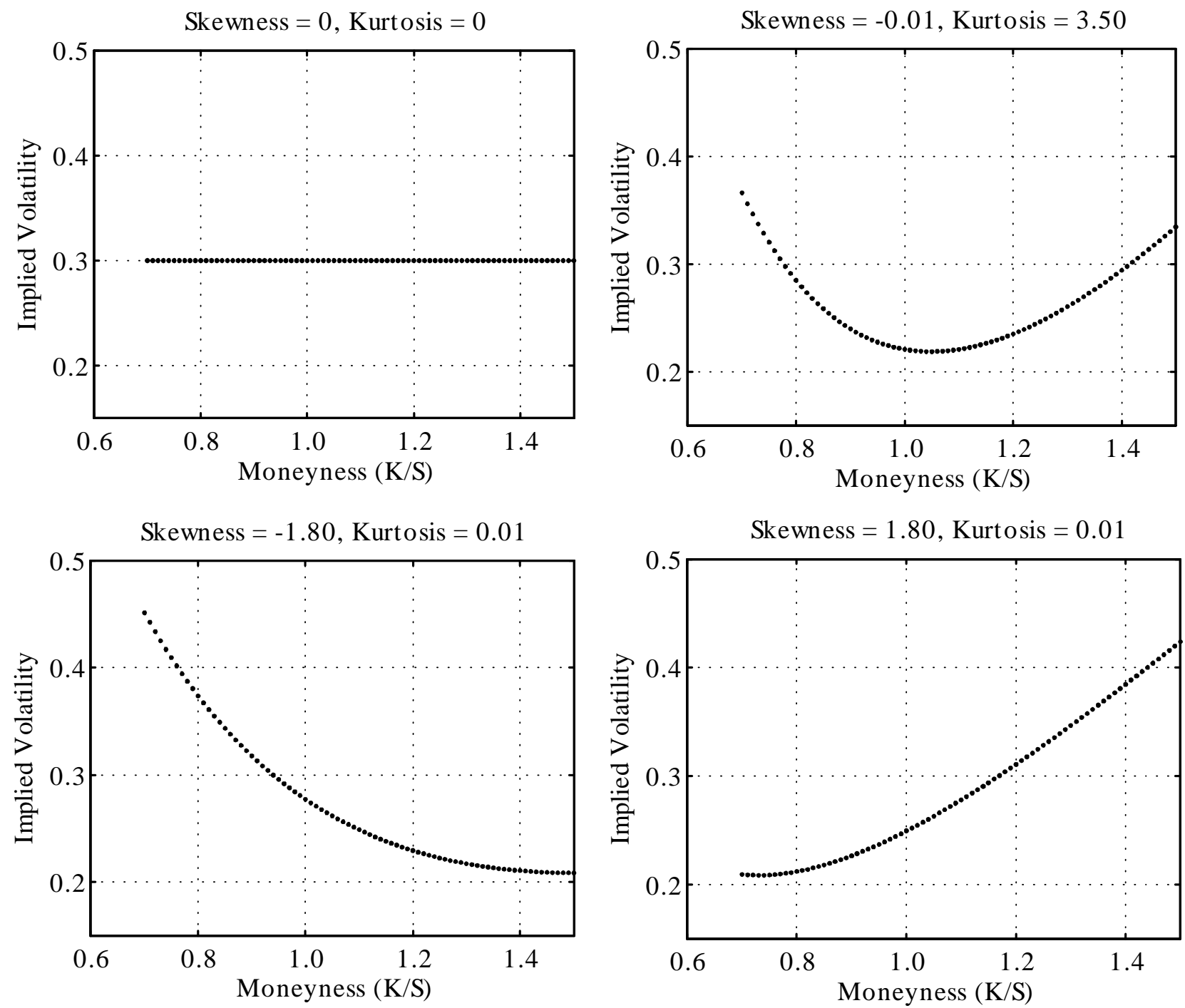

Notes to Figure: We use the approximate option valuation model in Backus et al (1997) to plot Black-Scholes implied volatility as a function of option moneyness, defined as strike price over stock price $K / S$. In the top left panel we set skewness and excess kurtosis to zero. In the top right panel excess kurtosis is positive at 3.5 but skewness is zero. In the bottom left panel, skewness is negative and and excess kurtosis is close to zero. In the bottom right panel, skewness is positive and excess kurtosis is again close to zero. 
Figure 2: Cumulative Returns on Fama-French and Carhart Four Factors. 1990-2012.
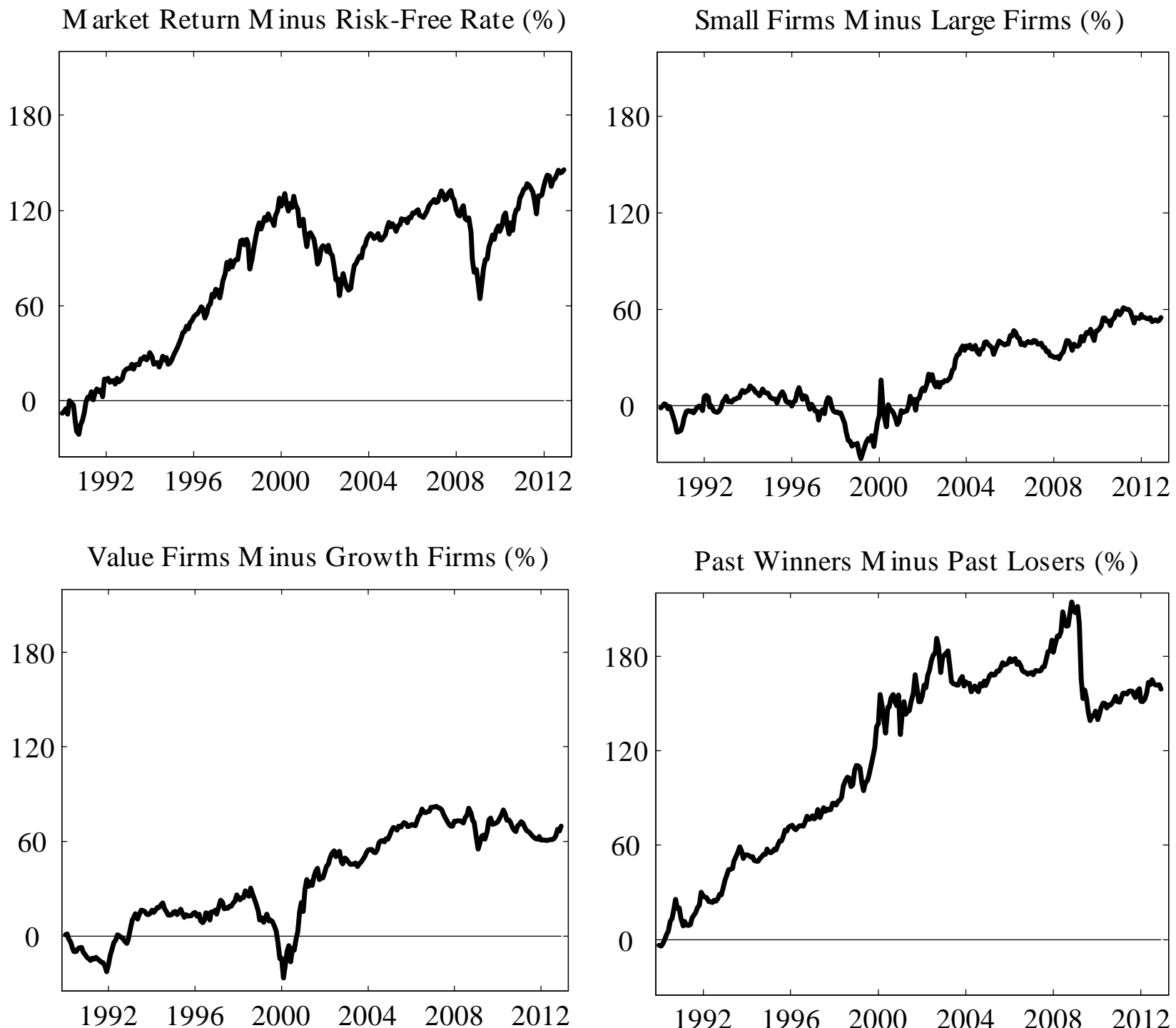

Past Winners Minus Past Losers (\%)

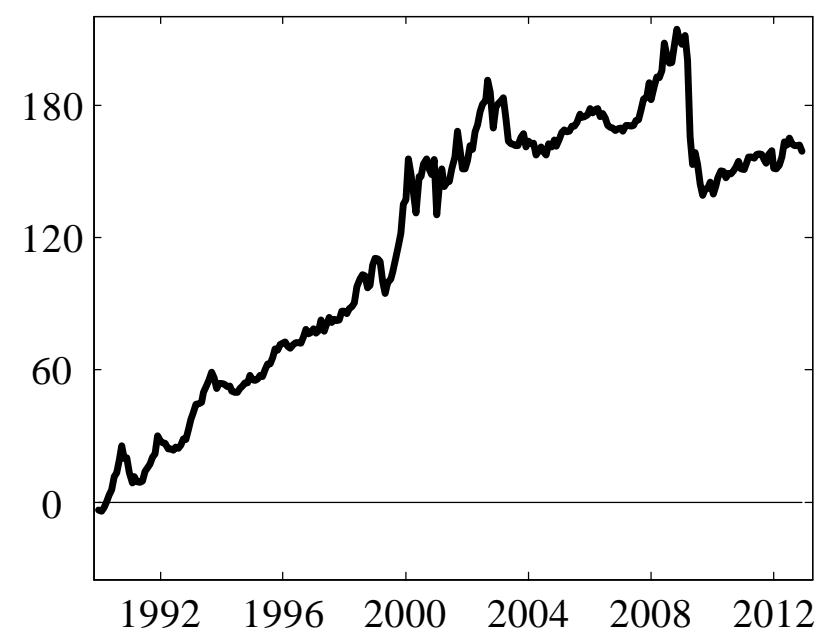

Notes to Figure: We plot the cumulative monthly return on the four equity market risk factors from Fama and French (1993) and Carhart (1997). 
Figure 3: VIX, SKEW and The Variance Risk Premium, 1990-2012.

CBOE Volatility Index (VIX)

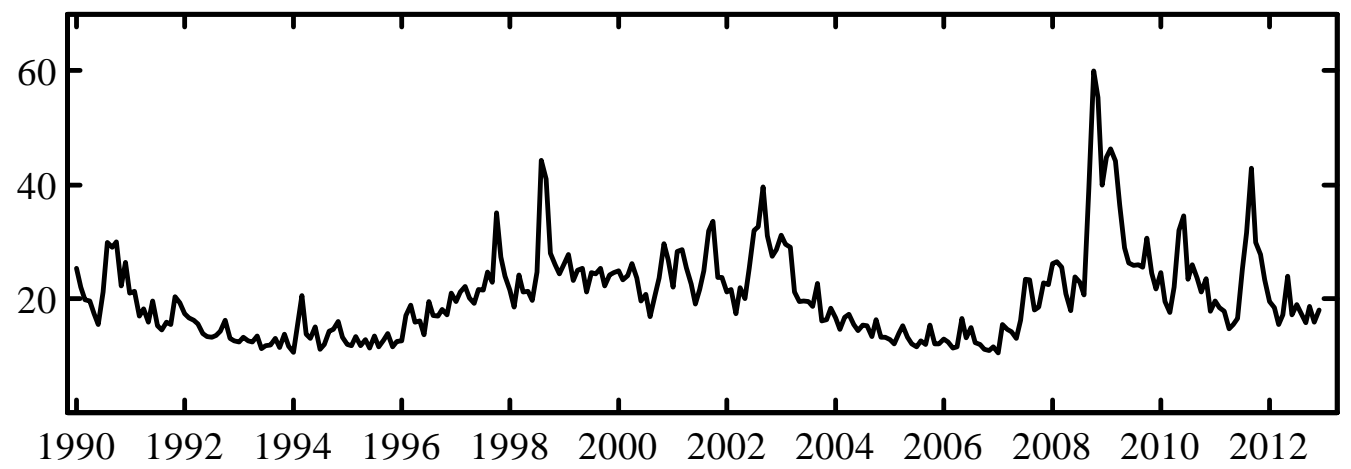

CBOE SKEW Index
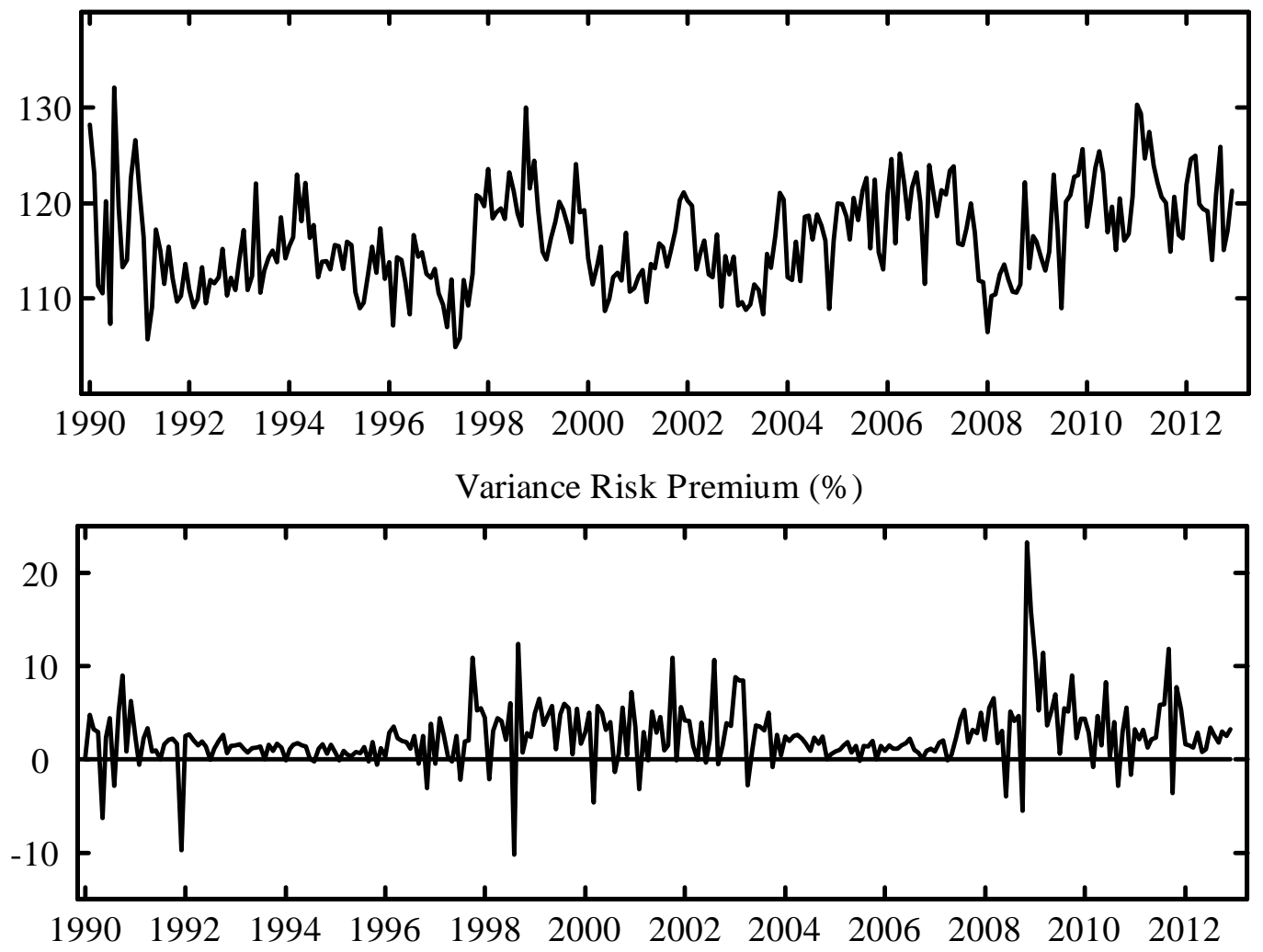

Notes to Figure: We plot end-of-month values of the CBOE S\&P500 option-implied volatility index, VIX (top panel, percent per year), the option-implied skewness index, SKEW (middle panel, index values), and the variance risk premium (percent per year), defined as the optionimplied variance less realized variance. 
Figure 4: Option Implied Volatility of Oil, Gold and Copper, 1990-2012.

Oil Option-Implied Volatility (\%)

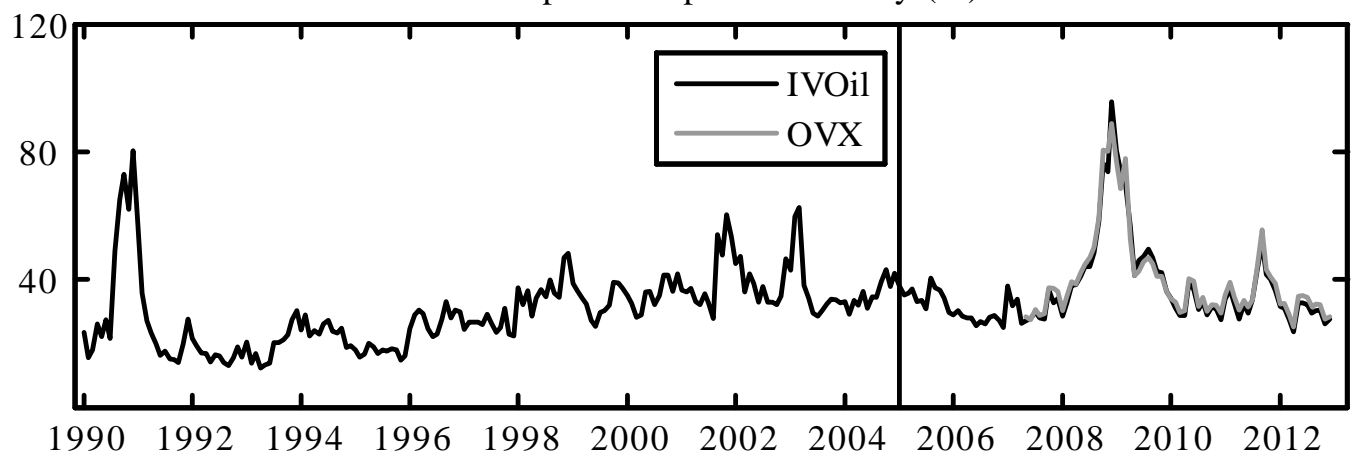

Gold Option-Implied Volatility (\%)

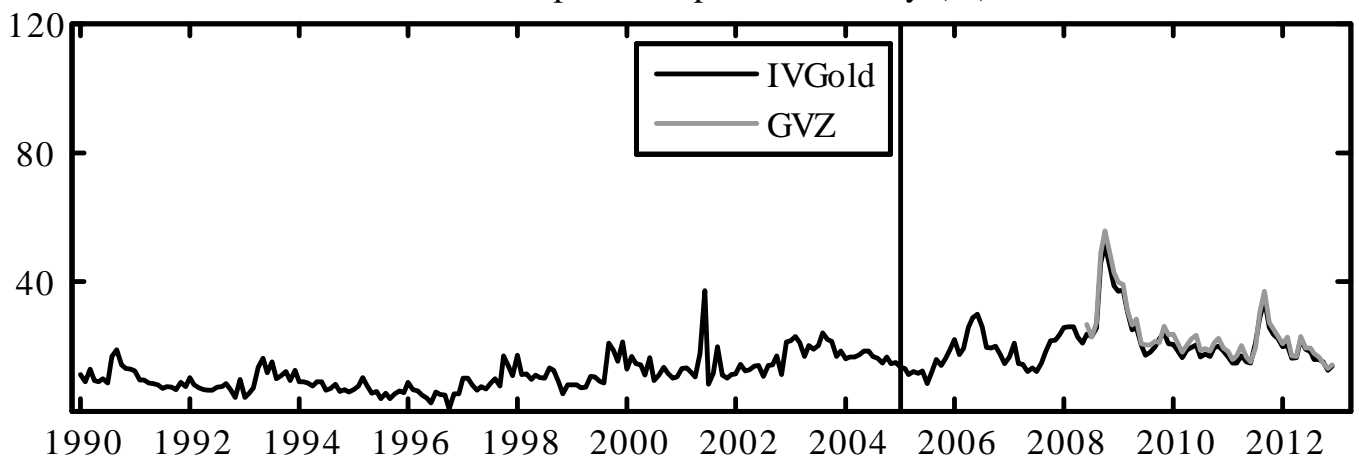

Copper Option-Implied Volatility (\%)

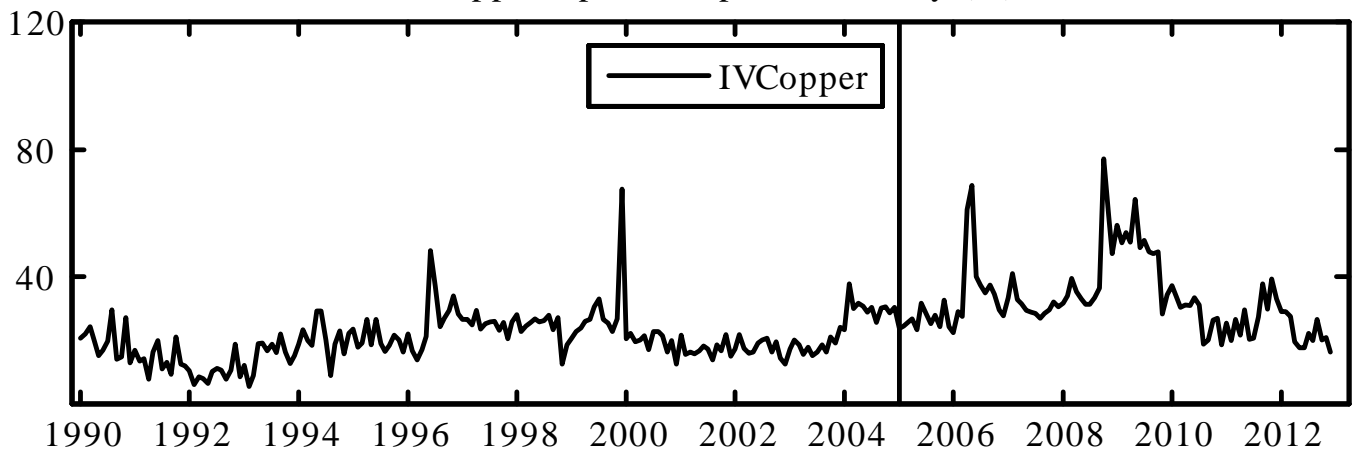

Notes to Figure: We plot end-of-month values of the CBOE oil volatility index, OVX (top panel grey line), our futures-option-implied oil volatility, IVOil (top panel, black line), the CBOE gold volatility index, OVZ (middle panel, grey line), our futures-option-implied gold volatility, IVGold (middle panel, black line), and our futures-option-implied copper volatility, IVCopper (bottom panel). 
Table 1: Stock Returns Based on Information in Individual Equity Options

\begin{tabular}{|c|c|c|c|c|c|c|c|}
\hline & & \multicolumn{6}{|c|}{ Quintile Portfolio Returns and Alphas } \\
\hline & & 1 & 2 & 3 & 4 & 5 & $5-1$ \\
\hline \multicolumn{8}{|c|}{ Panel A: Relative BSIV of Puts and Calls } \\
\hline \multicolumn{2}{|c|}{ Four-Week Mean Return (\%) } & 0.65 & 0.76 & 0.72 & 0.91 & 1.05 & $\begin{array}{c}0.40 \\
(3.12)\end{array}$ \\
\hline \multicolumn{2}{|c|}{ Four-Week Alpha (\%) } & -0.14 & -0.02 & -0.07 & 0.16 & 0.38 & $\begin{array}{c}0.51 \\
(3.35)\end{array}$ \\
\hline \multicolumn{2}{|c|}{ One-Week Mean Return (\%) } & 0.10 & 0.16 & 0.18 & 0.27 & 0.30 & $\begin{array}{c}0.20 \\
(3.05)\end{array}$ \\
\hline \multicolumn{2}{|c|}{ One-Week Alpha (\%) } & -0.10 & -0.04 & -0.02 & 0.07 & 0.11 & $\begin{array}{c}0.21 \\
(3.33)\end{array}$ \\
\hline Pane & mplied Volatility Slopes & \multicolumn{6}{|c|}{ Quintile Portfolio Returns and Alphas } \\
\hline \multirow{2}{*}{\multicolumn{2}{|c|}{$\begin{array}{l}\text { Moneyness-based Slope } \\
\text { Weekly Excess Return }(\%)\end{array}$}} & 1 & 2 & 3 & 4 & 5 & $5-1$ \\
\hline & & 0.24 & 0.15 & 0.16 & 0.11 & 0.08 & $\begin{array}{l}-0.16 \\
(-2.19)\end{array}$ \\
\hline \multicolumn{2}{|c|}{ Weekly FF-3 Alpha (\%) } & 0.10 & 0.03 & 0.03 & -0.02 & -0.11 & $\begin{array}{l}-0.21 \\
(-2.93)\end{array}$ \\
\hline \multicolumn{8}{|c|}{ Volume-weighted Slope } \\
\hline \multicolumn{2}{|c|}{ Weekly Excess Return (\%) } & 0.26 & 0.21 & 0.14 & 0.15 & 0.07 & $\begin{array}{l}-0.19 \\
(-2.05)\end{array}$ \\
\hline \multicolumn{2}{|c|}{ Weekly FF-3 Alpha (\%) } & 0.14 & 0.08 & 0.04 & 0.04 & -0.05 & $\begin{array}{l}-0.19 \\
(-2.07) \\
\end{array}$ \\
\hline \multirow{2}{*}{\multicolumn{2}{|c|}{ Panel C: Model-free Higher Moments }} & \multicolumn{6}{|c|}{ Tercile Portfolio Returns } \\
\hline & & 1 & 2 & 3 & & $3-1$ & \\
\hline \multirow[t]{2}{*}{ Volatility } & Monthly Returns (\%) & 1.35 & 0.99 & 0.79 & & -0.56 & $(-0.71)$ \\
\hline & Char-Adj Return (\%) & 0.44 & 0.09 & 0.08 & & -0.36 & $(-0.57)$ \\
\hline \multirow[t]{2}{*}{ Skewness } & Monthly Returns (\%) & 1.45 & 1.04 & 0.63 & & -0.82 & $(-2.06)$ \\
\hline & Char-Adj Return (\%) & 0.57 & 0.21 & -0.22 & & -0.79 & $(-2.08)$ \\
\hline \multirow[t]{2}{*}{ Kurtosis } & Monthly Returns (\%) & 0.63 & 1.11 & 1.36 & & 0.72 & $(2.01)$ \\
\hline & Char-Adj Return $(\%)$ & -0.25 & 0.31 & 0.46 & & 0.71 & $(2.12)$ \\
\hline
\end{tabular}

Notes to Table: Panel A is extracted from Table 4 of Cremers and Weinbaum (2010). Panel B is extracted from Table 3 of Xing, Zhang, and Zhao (2010). Panel C is part of Table 2 of Conrad, Dittmar, and Ghysels (2013). The sample period is 1996-2005 in all three studies. 
Table 2: Stock Returns Based on Exposure to Market Index Option Information

\begin{tabular}{|c|c|c|c|c|c|c|}
\hline & \multicolumn{6}{|c|}{ Quintile Portfolios } \\
\hline & 1 & 2 & 3 & 4 & 5 & $5-1$ \\
\hline $\begin{array}{c}\text { Panel A: Market Volatility VIX } \\
\text { Average Return }(\%)\end{array}$ & 1.64 & 1.39 & 1.36 & 1.21 & 0.60 & $\begin{array}{c}-1.04 \\
(-3.90)\end{array}$ \\
\hline $\begin{array}{c}\text { FF-3 Alpha }(\%) \\
\text { Sample Period: } 1986-2000\end{array}$ & 0.30 & 0.09 & 0.08 & -0.06 & -0.53 & $\begin{array}{l}-0.83 \\
(-2.93)\end{array}$ \\
\hline $\begin{array}{c}\text { Panel B: Market Skewness } \\
\text { Average Return }(\%)\end{array}$ & 1.22 & 1.12 & 0.89 & 0.84 & 0.63 & $\begin{array}{l}-0.59 \\
\mathbf{( - 1 . 8 8 )}\end{array}$ \\
\hline $\begin{array}{c}\text { Carhart Alpha (\%) } \\
\text { Sample Period: 1996-2007 }\end{array}$ & 0.52 & 0.27 & 0.02 & -0.13 & -0.28 & $\begin{array}{l}-0.80 \\
(-2.42)\end{array}$ \\
\hline $\begin{array}{l}\text { Panel C: Variance Risk Premium } \\
25 \text { Size/BM Portfolios }\end{array}$ & & & & & & \\
\hline Average Excess Return (\%) & 0.38 & 0.74 & 0.78 & 0.97 & 0.96 & $\begin{array}{c}0.58 \\
(2.51)\end{array}$ \\
\hline FF-3 Alpha (\%) & -0.42 & -0.05 & 0.02 & 0.22 & 0.27 & $\begin{array}{c}0.69 \\
(3.33)\end{array}$ \\
\hline $\begin{array}{l}100 \text { Size/BM Portfolios } \\
\text { Average Excess Return (\%) }\end{array}$ & 0.48 & 0.72 & 0.80 & 0.94 & 0.97 & $\begin{array}{c}0.49 \\
(2.14)\end{array}$ \\
\hline FF-3 Alpha (\%) & -0.37 & -0.08 & 0.04 & 0.19 & 0.28 & $\begin{array}{c}0.65 \\
(2.70)\end{array}$ \\
\hline Sample Period: 1990-2010 & & & & & & \\
\hline
\end{tabular}

Notes to Table: Panel A is extracted from Table 1 of Ang, Hodrick, Xing, and Zhang (2006). Panel B is extracted from Table 3 of Chang, Christoffersen, and Jacobs (2013). Panel C is extracted from Table 7 of Bali and Zhou (2013). 
Table 3: Stock Returns Based on Exposure to Commodity Option Information

\begin{tabular}{|c|c|c|c|c|c|c|}
\hline & \multicolumn{6}{|c|}{ Quintile Portfolios } \\
\hline & 1 & 2 & 3 & 4 & 5 & $5-1$ \\
\hline Panel A: Crude Oil & & & & & & \\
\hline Average Return (\%) & 1.08 & 0.93 & 0.58 & 0.53 & 0.42 & $\begin{array}{l}-0.66 \\
(-2.49)\end{array}$ \\
\hline Carhart Alpha (\%) & 0.51 & 0.37 & 0.05 & -0.05 & -0.24 & $\begin{array}{c}-0.75 \\
\mathbf{( - 1 . 9 1 )} \\
\end{array}$ \\
\hline $\begin{array}{c}\text { Panel B: Gold } \\
\text { Average Return }(\%)\end{array}$ & 0.51 & 0.45 & 0.52 & 0.68 & 1.03 & $\begin{array}{c}0.53 \\
(1.20)\end{array}$ \\
\hline Carhart Alpha (\%) & -0.10 & -0.10 & 0.00 & 0.11 & 0.43 & $\begin{array}{c}0.54 \\
(1.61) \\
\end{array}$ \\
\hline $\begin{array}{c}\text { Panel C: Copper } \\
\text { Average Return }(\%)\end{array}$ & 0.61 & 0.41 & 0.50 & 0.71 & 0.93 & $\begin{array}{c}0.31 \\
(1.39)\end{array}$ \\
\hline Carhart Alpha (\%) & 0.01 & -0.13 & -0.04 & 0.15 & 0.31 & $\begin{array}{c}0.30 \\
(0.89)\end{array}$ \\
\hline
\end{tabular}

Notes to Table: The results on stock exposure to oil option-implied volatility IVOil in Panel A are from Christoffersen and Pan (2014). Panel B (C) reports expected returns and alphas of portfolios based on innovations in gold (copper) option-implied volatility IVGold (IVCopper). The sample period is January 2005 through December 2012. 
Table 4: Sharp Ratios of Mean-Variance Portfolios Using Option-Implied Information

\begin{tabular}{l|ccc|ccc}
\hline \multicolumn{1}{c|}{ Portfolios } & \multicolumn{3}{c|}{ Sample 1 } & \multicolumn{3}{c}{ Sample 2 } \\
& Daily & Weekly & Biweekly & Daily & Weekly & Biweekly \\
\hline 1/N & 0.59 & 0.60 & 0.61 & 0.50 & 0.50 & 0.50 \\
Shortsales constrained & 0.45 & 0.46 & 0.45 & 0.66 & 0.68 & 0.67 \\
Shortsales constrained + implied volatility & 0.68 & 0.60 & 0.59 & 0.41 & 0.37 & 0.33 \\
Shortsales constrained + volatility risk premium & $\mathbf{0 . 9 2}$ & $\mathbf{0 . 8 0}$ & 0.71 & 0.77 & 0.62 & 0.53 \\
Shortsales constrained + implied skewness & $\mathbf{1 . 0 1}$ & $\mathbf{0 . 8 4}$ & $\mathbf{0 . 7 9}$ & $\mathbf{1 . 0 1}$ & 0.81 & 0.73 \\
Shortsales constrained + call-put volatility spread & $\mathbf{1 . 4 3}$ & $\mathbf{0 . 9 3}$ & $\mathbf{0 . 8 1}$ & $\mathbf{1 . 3 6}$ & $\mathbf{0 . 9 1}$ & 0.75 \\
\hline
\end{tabular}

Notes to Table: This table is extracted from Table 2 and Table 6 of DeMiguel, Plyakha, Uppal, Vikov (2014). 
Table 5: Returns and Betas from Historical and Option-Implied Information

\begin{tabular}{l|cccccc}
\hline & \multicolumn{7}{|c}{ Quintile Portfolios } \\
\cline { 2 - 7 } & 1 & 2 & 3 & 4 & 5 & $5-1$ \\
\hline Panel A: Daily & & & & & & \\
Historical Beta & 0.48 & 0.71 & 0.88 & 1.09 & 1.52 & 1.04 \\
Realized Return (\%) & 4.50 & 4.94 & 4.99 & 7.05 & 5.09 & 0.60 \\
Option-Implied Beta & 0.66 & 0.83 & 0.96 & 1.12 & 1.45 & 0.79 \\
Realized Return (\%) & 4.15 & 4.82 & 5.58 & 6.54 & 9.72 & 5.57 \\
\hline Panel B: Monthly & & & & & & \\
Historical Beta & 0.36 & 0.66 & 0.90 & 1.20 & 1.79 & 1.43 \\
Realized Return (\%) & 4.79 & 5.75 & 5.82 & 8.45 & 4.05 & -0.74 \\
Option-Implied Beta & 0.65 & 0.83 & 0.98 & 1.15 & 1.49 & 0.84 \\
Realized Return (\%) & 3.98 & 6.14 & 6.11 & 6.65 & 11.61 & 7.63 \\
\hline
\end{tabular}

Notes to Table: This table is extracted from Table 1 of Buss and Vilkov (2012). 
2014-46: Alessandro Giovannelli and Tommaso Proietti: On the Selection of Common Factors for Macroeconomic Forecasting

2014-47: $\quad$ Martin M. Andreasen and Andrew Meldrum: Dynamic term structure models: The best way to enforce the zero lower bound

2014-48: $\quad$ Tim Bollerslev, Sophia Zhengzi Li and Viktor Todorov: Roughing up Beta: Continuous vs. Discontinuous Betas, and the Cross-Section of Expected Stock Returns

2914-49: $\quad$ Tim Bollerslev, Viktor Todorov and Lai Xu: Tail Risk Premia and Return Predictability

2014-50: Kerstin Gärtner and Mark Podolskij: On non-standard limits of Brownian semistationary

2014-51: Mark Podolskij : Ambit fields: survey and new challenges

2014-52: Tobias Fissler and Mark Podolskij: Testing the maximal rank of the volatility process for continuous diffusions observed with noise

2014-53: Cristina M. Scherrer: Cross listing: price discovery dynamics and exchange rate effects

2014-54: Claudio Heinrich and Mark Podolskij: On spectral distribution of high dimensional covariation matrices

2014-55: Gustavo Fruet Dias and Fotis Papailias: Forecasting Long Memory Series Subject to Structural Change: A Two-Stage Approach

2014-56: Torben G. Andersen, Nicola Fusari and Viktor Todorov: The Risk Premia Embedded in Index Options

2014-57: Eduardo Rossi and Paolo Santucci de Magistris: Indirect inference with time series observed with error

2014-58: $\quad$ Anders Bredahl Kock and Haihan Tang: Inference in High-dimensional Dynamic Panel Data Models

2015-01 Tom Engsted, Simon J. Hviid and Thomas Q. Pedersen: Explosive bubbles in house prices? Evidence from the OECD countries

2015-02: $\quad$ Tim Bollerslev, Andrew J. Patton and Wenjing Wang: Daily House Price Indices: Construction, Modeling, and Longer-Run Predictions

2015-03: Christian M. Hafner, Sebastien Laurent and Francesco Violante: Weak diffusion limits of dynamic conditional correlation models

2015-04: Maria Eugenia Sanin, Maria Mansanet-Bataller and Francesco Violante: Understanding volatility dynamics in the EU-ETS market

2015-05: Peter Christoffersen and Xuhui (Nick) Pan: Equity Portfolio Management Using Option Price Information 